\title{
Impacto da vegetação nos microclimas urbanos e no conforto térmico em espaços abertos em função das interações solo-vegetação-atmosfera
}

\author{
The impact of vegetation in urban microclimates and \\ thermal comfort as a function of soil-vegetation- \\ atmosphere interactions
}

\section{Paula Shinzato \\ Denise Helena Silva Duarte}

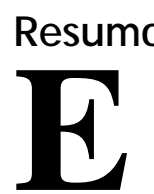

ste estudo é parte de uma investigação sobre o impacto da vegetação nos microclimas urbanos, abaixo do dossel, em função das interações solo-vegetação-atmosfera. Esta pesquisa teve como objetivos: (1) quantificar o impacto da vegetação por meio de medições microclimáticas; (2) fazer uso do modelo preditivo ENVI-met 3.1 para simular o efeito microclimático da vegetação com diferentes características; (3) quantificar o impacto no conforto humano, com a aplicação do índice de conforto externo TEP Temperatura Equivalente Percebida. O método é indutivo, por meio de medições de campo realizadas no Parque Tenente Siqueira Campos (Trianon), na cidade de São Paulo, com o registro de dados microclimáticos por duas estações meteorológicas dentro do parque e o levantamento de dados de estações fixas externas ao parque, além das variáveis do dossel arbóreo e do solo; e dedutivo, após a calibração entre dados medidos e simulados pelo modelo ENVI-met 3.1 e simulações de um mesmo cenário, variando-se as características do dossel. Dois métodos não destrutivos indiretos foram utilizados para estimar o índice de área foliar (IAF): com o equipamento LAI-2000 e pós-processamento de fotos hemisféricas. Dentre todas as variáveis medidas e simuladas, os valores da temperatura radiante média são os mais impactados sob o dossel da vegetação arbórea, influenciando diretamente o conforto térmico.

Palavras-chaves: Vegetação urbana. Microclima urbano. Índice de área foliar. ENVImet.
Abstract
This study is part of an investigation of the impact of vegetation on urban microclimates, under the canopy, as a function of soil-vegetation-atmosphere interactions. The aim of this study was: (1) to quantify the impact of vegetation based on microclimatic measurements (2) using the predictive model ENVI- met 3.1 to simulate the microclimatic effect of vegetation with different characteristics; (3) impact on human comfort with the application of external comfort index TEP - Temperature of Equivalent Perception. The method is inductive, with field measurements at Tenente Siqueira Campos Park (Trianon), in the city of São Paulo, for monitoring microclimatic data with two meteorological stations inside the park and for the survey of data from fixed stations outside the park, besides canopy and soil variables; and deductive, after calibration between measured and simulated data by ENVI-met 3.1 model and simulations of the same scenario, varying the characteristics of the canopy. Two indirect non-destructive methods were used to estimate the leaf area index (LAI): with LAI-2000 equipment and post-processing of hemispheric photos. Among all measured and simulated variables, the values for mean radiant temperature are the most impacted under the canopy of the tree vegetation, directly influencing thermal comfort.
Keywords: Urban vegetation. Urban microclimate. Leaf area index. ENVI-met.

Paula Shinzato Universidade de São Paulo São Paulo - SP - Brasil

Denise Helena Silva Duarte Universidade de São Paulo São Paulo - SP - Brasil

Recebido em 02/04/17

Aceito em 30/07/17

SHINZATO, P.; DUARTE, D. H. S. Impacto da vegetação nos microclimas urbanos e no conforto térmico em espaços abertos em função das interações solo-vegetação-atmosfera. Ambiente Construído, Porto Alegre, v. 18, n. 2, p. 197215, abr./jun. 2018.

ISSN 1678-8621 Associação Nacional de Tecnologia do Ambiente Construído. http:// dx. doi.org/ 10.1590/ s1678-86212018000200250 


\section{Introdução}

O processo de urbanização mudou a relação entre a sociedade e o ambiente natural. A consequência direta desse processo é a modificação nas características das superfícies urbanas (STONE, 2012).

A ausência da vegetação influencia no aumento da temperatura do ar devido ao aquecimento das superfícies (pisos, fachadas e coberturas) ao longo do dia e na redução de superfícies evaporativas que realizam trocas térmicas úmidas. Além disso, outros fatores também contribuem para esse efeito: mudanças na geometria do tecido urbano (relação altura e largura do canyon), uso de materiais que armazenam grande parte do calor sensível devido às suas propriedades térmicas e emissão de calor antropogênico gerado pela queima de combustível fóssil (OKE, 1978).

Segundo Stone (2012), três principais estratégias precisam ser consideradas para mitigar o aquecimento nos grandes centros urbanos:

(a) plantio de árvores e planejamento de novas configurações com o uso da vegetação (teto verde, parede verde, jardins ao longo da altura dos edifícios (sky gardens);

(b) aumento do albedo, incorporando técnicas para menor aquecimento das coberturas ou substituição do revestimento por materiais mais refletivos; e

(c) implementação de programas de eficiência energética com o compromisso de reduzir as emissões de gases do efeito estufa.

Dessa forma, inserir a vegetação em áreas urbanas é uma das principais estratégias para mitigar o aquecimento nas cidades, uma vez que as plantas representam um importante papel como regulador do clima urbano (CHEN; WONG, 2006). Da mesma forma o uso da vegetação como elemento de proteção da envoltória do edifício atua positivamente sobre os fluxos de calor nas coberturas e fachadas, o que representa uma importante ferramenta para o controle térmico passivo no interior das edificações (MATHEUS et al., 2016; CHEN; WONG, 2006).

No microclima, o efeito da vegetação ocorre por dois mecanismos: evapotranspiração e sombreamento. O processo de evapotranspiração está diretamente ligado à resistência estomática que relaciona a quantidade dos estômatos nas folhas com uma adequada condição no solo (disponibilidade de água) e na atmosfera (disponibilidade de luz).

Nesse sentido, o índice de área foliar (IAF) tem uma relação direta com a quantidade de luz, energia e consumo de $\mathrm{CO}_{2}$. Segundo Chen e Black (1992), o conceito do IAF considera metade do total da área fotossinteticamente ativa das folhas em relação à sua área de projeção no solo. O IAF é um índice que influencia diretamente na interceptação e absorção da luz na copa, assim como nas trocas de calor e taxas de evaporação com a atmosfera. À medida que a cultura vai crescendo aumenta o número de folhas e, dessa maneira, com o aumento da superfície foliar e do número de folhas utilizadas na fotossíntese, cresce a absorção de $\mathrm{CO}_{2}$, o que estimula cada vez mais a evapotranspiração, resultando em acréscimo de matéria seca, que sintetiza todas as relações planta-meio (ONG, 2002).

Dessa forma, o IAF é um parâmetro-chave para se determinar uma série de processos ecológicos e fisiológicos como fotossíntese e evapotranspiração, o que possibilita a previsão das taxas de troca de energia entre vegetação e atmosfera, a curva de crescimento futuro e as diferenças na estrutura da copa devido à poluição do ar e mudança climática (ONG, 2002).

Os métodos de medição do IAF podem ser classificados em duas principais categorias: métodos destrutivos diretos e métodos não destrutivos indiretos. $\mathrm{O}$ método direto baseia-se no cálculo da área média de folhas individuais coletadas e, com base nesses dados, estima-se o IAF para toda a copa da árvore. O método indireto envolve cálculos a partir da atenuação da radiação pelo dossel da copa, segundo análise da distribuição geométrica das aberturas entre as folhas (gap fraction distribution), e pode ser feito com um analisador de dossel ou por pós-processamento de fotos hemisféricas (BREDA, 2003).

Se os valores de IAF oferecem um parâmetro médio da densidade foliar de uma copa, a informação sobre a estrutura da copa é dada pela medida da distribuição geométrica das aberturas (gap fraction). Assim, o gap fraction é definido como a fração de céu aberto acima de um determinado ponto no solo sem nenhuma interferência do dossel vegetal. Dessa forma, representa a porcentagem de vazios existentes na copa, considerando que os raios solares atravessam a copa sem serem bloqueados ou tocados pelas folhas (ROSS, 1981).

Os benefícios provenientes da vegetação no microclima já foram constatados em diversos estudos, por meio de medições microclimáticas locais que verificaram a redução na temperatura do ar entre $1,5^{\circ} \mathrm{C}$ e $4,0^{\circ} \mathrm{C}$, durante o período do verão (OKE, 1989; GIVONI, 1998; SAILOR, 1995, SHASHUA-BAR; HOFFMAN, 2004; DIMOUDI; NOKOLOPOULOU, 2003; CHEN; WONG, 2006). 
Considerando-se as interações solo-vegetaçãoatmosfera, o efeito da vegetação no microclima depende do ambiente urbano em que está inserido, considerando-se não apenas as características das árvores (densidade foliar, saúde da planta), mas também as condições locais (disponibilidade de água) e a forma urbana do entorno (COUTTS et al., 2012).

Os estudos de Wienert e Kuttler (2005) mostram que as diferenças máximas na temperatura do ar entre as áreas urbanas e rurais para climas temperados no período noturno podem chegar a $6,0^{\circ} \mathrm{C}$ em climas temperados, e de $1,5^{\circ} \mathrm{C}$ a $4,0{ }^{\circ} \mathrm{C}$ para os climas tropicais (CHOW; ROW, 2006). Com medições, Santamouris (2001) constatou no interior do parque e no entorno na cidade de Atenas, Grécia que a variação das temperaturas foi de $1,5^{\circ} \mathrm{C}$ no parque; no entorno, cerca de $3,0^{\circ} \mathrm{C}$ durante o dia.

Estudos realizados por Chen e Wong (2006) em parque urbano, no centro de Cingapura, apontam os seguintes resultados para dez pontos de medição de campo em uma distância aproximada de $100 \mathrm{~m}$ entre os pontos, sendo cinco no interior e os demais entre as quadras residenciais (fora do parque): os pontos contidos no parque atingem temperaturas médias entre $25,2^{\circ} \mathrm{C}$ a $25,5^{\circ} \mathrm{C}$. Já os pontos situados nas quadras apontam temperaturas do ar superiores, de até $26,9{ }^{\circ} \mathrm{C}$, com diferenças de até $1,7^{\circ} \mathrm{C}$ se comparadas aos valores obtidos no parque.

Bowler et al. (2010) apresentam uma revisão sistemática para investigar se as intervenções em áreas verdes, por meio do plantio de árvores, criação de parques e colocação de tetos verdes, afetariam a temperatura do ar em uma área urbana. A maioria dos estudos investigou a temperatura do ar dentro dos parques e abaixo das copas das árvores, e os resultados indicaram que, em média, um parque urbano é $0,94{ }^{\circ} \mathrm{C}$ mais frio durante o dia, com base nos dados observados nas áreas verdes existentes.

Apesar dos avanços na quantificação dos efeitos da vegetação no microclima, ainda são poucos os estudos preditivos voltados para climas tropicais e subtropicais, faltando dados sobre as características dos materiais (fachadas e coberturas), tipo da vegetação e solo (EMMANUEL; JOHANSSON, 2006). Sendo assim, o estudo das interações locais entre solo-vegetação-atmosfera se faz necessário pelo potencial da vegetação para amenizar o desconforto pelo calor em espaços abertos, principalmente durante o dia.

Este estudo é parte de uma investigação sobre o impacto da vegetação nos microclimas urbanos, abaixo do dossel, em função das interações solovegetação-atmosfera. Esta pesquisa teve como objetivos: (a) quantificar o impacto da vegetação no microclima (umidade específica, temperatura do ar, temperatura média radiante, direção e velocidade dos ventos) por meio de medições microclimáticas;

(b) fazer uso do modelo preditivo ENVI-met 3.1 para simular o efeito microclimático da vegetação com diferentes características (valores de IAF, formato da copa);

(c) quantificar o impacto no conforto humano, com a aplicação do índice de conforto externo temperatura equivalente percebida (TEP) para se verificar a contribuição da vegetação nas condições de conforto térmico em ambientes abertos.

\section{Método}

O método é indutivo, por meio de medições de campo durante o período de primavera no Parque Tenente Siqueira Campos (Trianon), na cidade de São Paulo, com o registro de dados microclimáticos por duas estações meteorológicas dentro do parque e o levantamento de dados de estações fixas externas ao parque, além das variáveis do dossel e do solo. Assim como dedutivo, após a calibração entre dados medidos e simulados pelo modelo ENVI-met 3.1 e a simulação de um mesmo cenário, variando-se as características do dossel.

Foram realizados os seguintes levantamentos de campo, a fim de se verificar as condições microclimáticas e as características da vegetação (IAF das copas) no Parque Trianon: medição das variáveis microclimáticas e medição do índice de área foliar.

Posteriormente, foram obtidos dados de duas estações fixas de referência, uma localizada no Aeroporto de Congonhas (WMO 83780) e outra pertencente ao IAG-USP, localizada no Parque de Ciência e Tecnologia da USP, na Água Funda (WMO 83004), ambas na zona sul de São Paulo. Foi realizada a análise comparativa dos dados para o período da medição de campo.

Tendo em mãos a análise dos dados medidos em campo e o levantamento da vegetação existente, foram feitas simulações computacionais preliminares com a utilização do ENVI-met 3.1 para calibrar o modelo em relação às condições microclimáticas medidas no parque Trianon. O modelo computacional adotado considera a densidade de folhas, as características do solo e as condições climáticas locais para simular em microescala as interações solo-vegetaçãoatmosfera. 
Em seguida foram feitas as simulações paramétricas com vegetação, considerando-se a variação nas características da vegetação (tipo e valores de IAF) e diferentes velocidades dos ventos. Uma vez concluídas as simulações, partiu-se para a análise dos resultados, comparando-se as medições com as simulações realizadas, na busca do estabelecimento de um parâmetro para os efeitos microclimáticos da vegetação.

O índice TEP (MONTEIRO; ALUCCI, 2012) foi aplicado a partir das condições de temperatura do ar, umidade relativa do ar, temperatura média radiante e velocidade dos ventos para se verificar o efeito no conforto térmico das pessoas abaixo do dossel. A Tabela 1 apresenta as faixas interpretativas consideradas pelo TEP.

\section{Medições microclimáticas}

O Parque Tenente Siqueira Campos (Parque Trianon) está localizado a 233' $42^{\prime \prime}$ Sul e 463' $24^{\prime \prime}$ Oeste. Apresenta uma área total de $48.600 \mathrm{~m}^{2}$, delimitada pelas vias: Avenida Paulista, Rua Peixoto Gomide, Alameda Jaú e Alameda Casa Branca. O Parque possui hoje uma das poucas reservas remanescentes de Mata Atlântica da região. Foram realizadas medições microclimáticas das variáveis de temperatura do ar, umidade do ar, radiação solar, temperatura de globo, temperatura do solo, direção e velocidade dos ventos com duas estações meteorológicas Campbell Scientific, entre os dias 13 e 16 de novembro de 2013, totalizando quatro dias e três noites. A Figura 1 mostra a localização do Parque Trianon na Avenida Paulista e o entorno dos pontos de medição.

Conforme indica o Centro de Previsão do Tempo e Estudos Climáticos (CPTEC) ${ }^{1}$, no período de verão ocorrem mudanças rápidas nas condições diárias do tempo, levando à ocorrência de chuvas de curta duração e forte intensidade na região Sudeste, principalmente no período da tarde. Dessa forma, preferiu-se realizar a medição microclimática no mês de novembro, antes do período do verão.

O monitoramento dos dados iniciou-se após três dias sem chuvas na cidade de São Paulo, a fim de registrar dados microclimáticos em uma condição atmosférica mais estável. O Grupo de Micrometeorologia do Instituto de Astronomia, Geofísica e Ciências Atmosféricas (IAG) da USP ${ }^{2}$ gerou a média mensal dos valores horários de temperatura do ar para o mês de novembro, considerando-se os dados medidos no período de 1996 a 2015, monitorados pela estação meteorológica na Plataforma do IAG no Campus da USP em São Paulo. Os dados médios horários da estação do IAG no campus da USP variaram de $18^{\circ} \mathrm{C}$ a $25^{\circ} \mathrm{C}$.

A Figura 2 mostra a localização das estações em dois pontos no parque: ponto 1 , logo na entrada principal, em frente à Av. Paulista, e ponto 2, na parte central, próximo à área do playground.

\section{Tabela 1 - Faixas interpretativas para a TEP}

\begin{tabular}{cc} 
TEP $\left({ }^{\circ} \mathrm{C}\right)$ & Sensação \\
\hline$>50,0$ & extremo calor \\
$42,5 \sim 50,0$ & muito calor \\
$34,9 \sim 42,4$ & calor \\
$27,3 \sim 34,8$ & pouco calor \\
$25,4 \sim 27,2$ & leve calor \\
$21,5 \sim 25,3$ & neutralidade \\
$19,6 \sim 21,4$ & leve frio \\
$12,0 \sim 19,5$ & pouco frio \\
$4,4 \sim 11,9$ & frio \\
$4,3 \sim-3,2$ & muito frio \\
$<-3,2$ & extremo frio
\end{tabular}

Fonte: Monteiro e Alucci (2012).

1Disponível em: «ttp:// clima1.cptec.inpe.br/ estacoes/ >. Acesso em: jul. 2017.

${ }^{2}$ Grupo de Micrometeorologia do Instituto de Astronomia, Geofísica e Ciências Atmosféricas (IAG) da Universidade de São Paulo (USP), dados da estação meteorológica na Plataforma do IAG no Campus da USP. Disponível em: বhttp:// www.iag. usp.br/meteo/labmicro/ Data/Graficos/ SP/ data.html / >. Acesso em: jul. de 2017. 
Figura 1 - Localização do Parque Trianon na Av. Paulista e o entorno dos pontos de medição 1 e 2

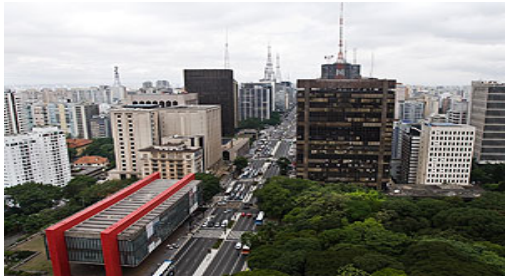

(a)

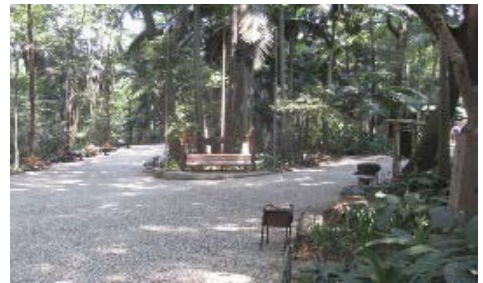

(b)

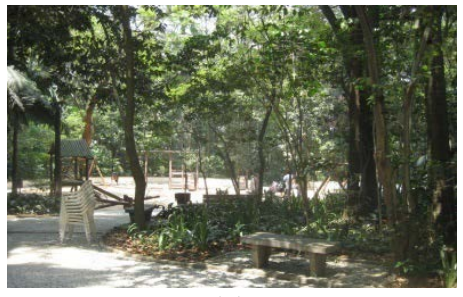

(c)

Fonte: (a) CET e Prefeitura de SP e (b) e (c) Labaut.

\section{Figura 2 - Parque Trianon na Av. Paulista com os dois pontos de medição microclimática onde foram locadas as estações}

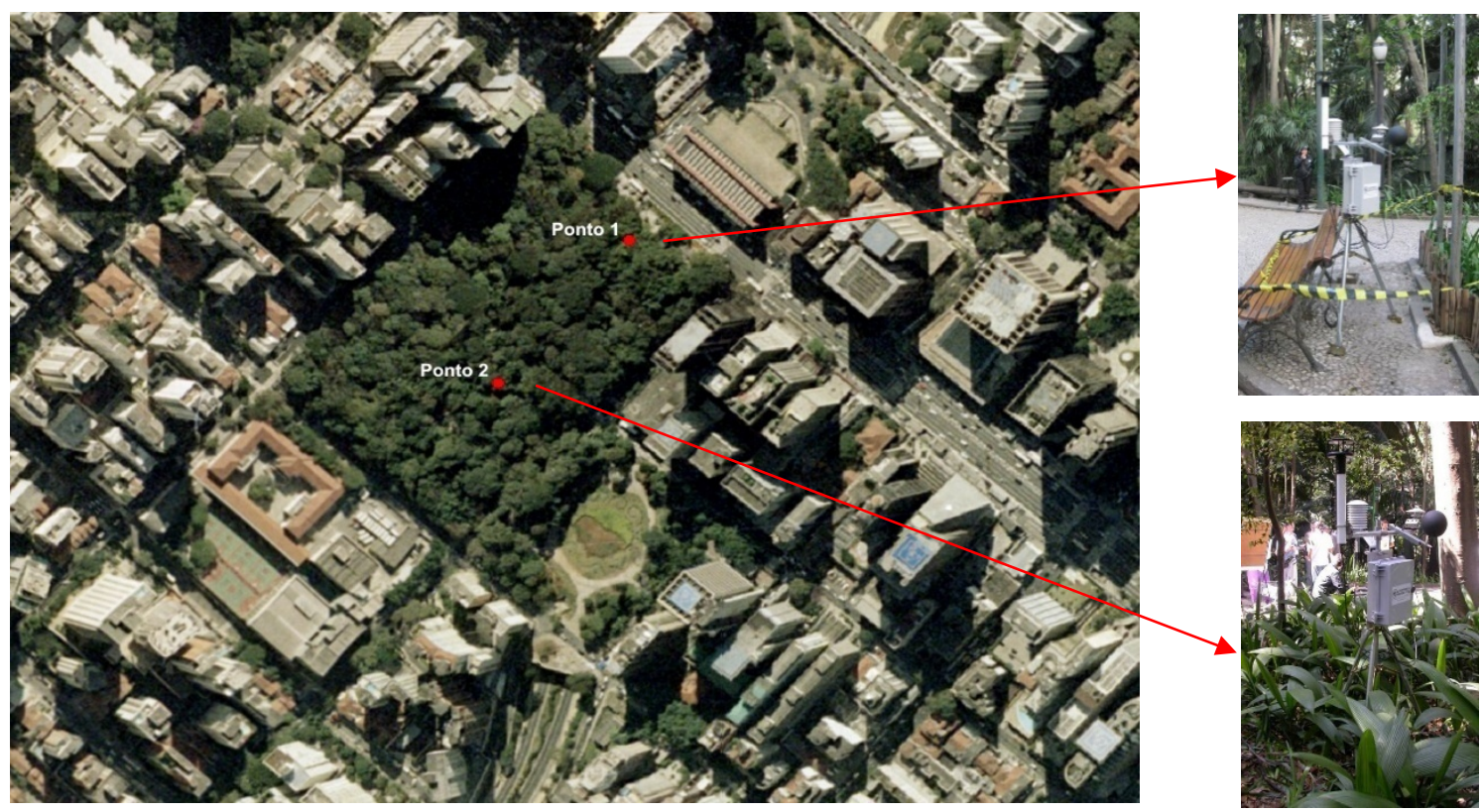

Fonte: Ortofoto digital (EMPLASA, 2007) e fotos de Paula Shinzato.

As variáveis registradas foram: temperatura do ar $\left({ }^{\circ} \mathrm{C}\right)$, umidade relativa do ar $(\%)$, velocidade do vento $(\mathrm{m} / \mathrm{s})$, direção do vento (graus) e temperatura de globo $\left({ }^{\circ} \mathrm{C}\right)$. As duas estações Campbell Scientific apresentam: datalogger para controle e armazenagem dos dados registrados CR800-STSW-NC, sensor de temperatura e umidade Vaisala HMP45C-L12 com proteção à radiação direta, piranômetro Kipp \& Zonen com protetor solar CMP3-L12, sensor para medir a temperatura de solo Probe 108-L12 e sensor de globo preto fosco de 15,2 cm de diâmetro, modelo L15-CSC. Os dados de velocidade e direção dos ventos foram medidos no Trianon por anemômetro ultrassônico bidimensional, modelo Gill 2-D Sonic Wind WINDSONIC1-L24, a 1,5 m de altura, com armazenamento de dados instantâneos da direção do vento a cada 1 minuto e registro da velocidade média nesse intervalo.

Foi concedida a autorização para se realizar a pesquisa de campo no Parque Trianon com a permanência das estações meteorológicas, inclusive no período noturno, pelo Departamento de Parques e Áreas Verdes (Depave-5) da Secretaria do Verde e Meio Ambiente (SVMA). O período de medição ficou restrito a quatro dias consecutivos, devido às questões de segurança dos equipamentos no parque. Foi feito um planejamento com grupos formados por professor, alunos de pós-graduação e iniciação científica do LABAUT/ USP para monitorar e cuidar dos equipamentos durante o dia, e foi solicitado o apoio da administração do parque para a vigilância dos equipamentos no período noturno. 


\section{Medições do Índice de Área Foliar (IAF)}

O IAF foi medido de duas formas, por dois métodos indiretos não destrutivos (BREDA, 2003), que envolvem a atenuação da radiação pelo dossel, a partir da análise da distribuição geométrica das aberturas entre as folhas (gap fraction distribution), e que podem ser realizados com um analisador de dossel ou por pós-processamento de fotos hemisféricas.

Nesta pesquisa foi utilizado o analisador de dossel LAI - 2000 (LI-COR, Lincoln, Nebraska) e o pósprocessamento de fotos hemisféricas (WEISS et al., 2004). As imagens foram registradas no Parque Trianon nos meses de agosto e setembro de 2012, sob céu parcialmente encoberto, utilizando-se a câmera digital Nikon COOLPIX 4500 com uma lente angular Nikon FC-E8 acoplada.

No planejamento das medições, foram definidas duas áreas no parque para o levantamento do IAF: uma por apresentar uma massa densa de vegetação, situada na parte central, e outra em uma área verde menos densa na entrada principal do parque na Av. Paulista. Em seguida foi estabelecida uma malha ortogonal dentro das áreas escolhidas, com espaçamento de $20 \mathrm{~m}$ x $20 \mathrm{~m}$, para se definir os 22 pontos a serem medidos (Figura 3a). No centro de cada célula, foram medidos os valores de IAF com o LAI-2000 (Figura 3b) e foi feito o registro das imagens hemisféricas a 1,70 m do solo (Figura 3c).

O LAI-2000 calcula o IAF efetivo (ZHENG; MOSKAL, 2009) pelas medidas de radiação feitas com um sensor óptico acoplado a uma lente grande angular $\left(148^{\circ}\right)$. Esse sensor de luz mede simultaneamente a radiação difusa em cinco bandas angulares distintas $\left(7^{\circ}, 23^{\circ}, 38^{\circ}, 53^{\circ}, 68^{\circ}\right)$, sendo constituído de cinco fotodiodos, cujas superfícies ativas estão arranjadas em anéis concêntricos (Figura 4a). A imagem do dossel, de forma quase hemisférica, é projetada dentro desses anéis, o que permite, para cada intervalo angular, a medição da radiação na banda e no ângulo zenital conhecido (Figura 4b). Um filtro óptico restringe a transmissão radiativa para comprimentos de onda menores que 490 nm (LI-COR, 1992)

O método por fotos hemisféricas foi aplicado em duas etapas:

(a) definição dos pontos e registro das fotos hemisféricas em campo, abaixo do dossel; e

(b) pós-processamento e análise das imagens hemisféricas pelo modelo CAN - EYE (WEISS et al., 2004), desenvolvido pelo National Institute of Agronomical Research (INRA) ${ }^{3}$.

\section{Figura 3 - (a) Definição dos 22 pontos para medição do IAF no Parque Trianon; (b) Medição do IAF com} o LAl-2000; (c) Registro das imagens hemisféricas

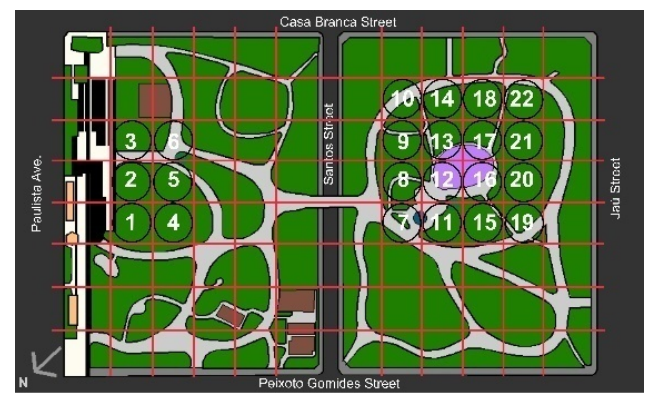

(a)

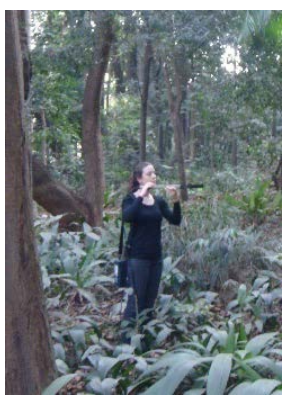

(b)

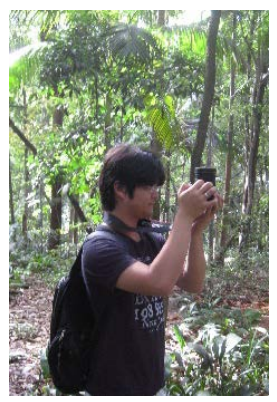

(c)

Figura 4 - (a) Estrutura interna do analisador de dossel LAI-2000; (b) Foto da lente grande angular do LAI-2000 com os 5 anéis concêntricos

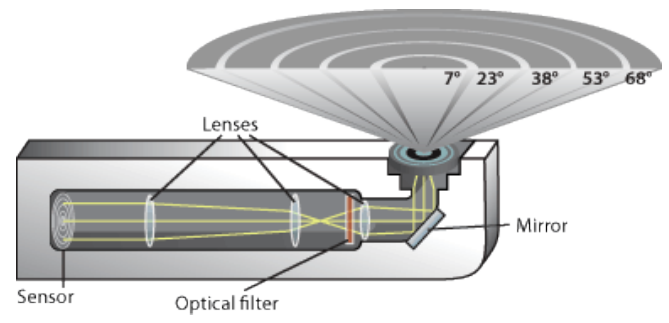

(a)

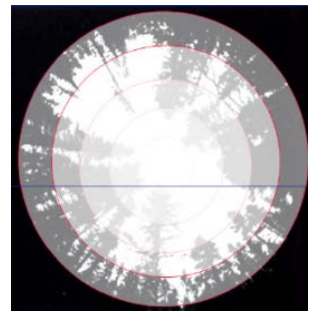

(b)

Fonte: LI-COR (1992).

3Disponível em: «ttps:// www4. paca.inra.fr/can-eye>. Acesso em: 15 jan. 2017. 
O modelo quantifica as aberturas entre as folhas (gap fraction distribution) de acordo com diferentes ângulos zenitais e azimutais, calculando os valores do IAF para um grupo arbóreo.

O modelo Can-Eye calcula o valor do IAF verdadeiro (true $L A I$ ), assim como estima o valor do IAF efetivo (effective $L A I$ ), o mesmo registrado pelo analisador de dossel LAI-2000. O IAF efetivo pode ser definido como a metade da área total de luz interceptada pelas folhas em relação à área de superfície do solo considerando-se a sobreposição das folhas e sua distribuição aleatória no espaço; já o IAF verdadeiro é definido como metade da área foliar total em relação à área de superfície do solo (ZHENG; MOSKAL, 2009). O valor verdadeiro é determinado pela lei de Poisson, assumindo que as folhas estão distribuídas de forma regular no dossel, sendo válido apenas para espécies com copas homogêneas. Conforme mostra a Equação 1, a relação entre o IAF verdadeiro e efetivo é dada pela expressão:

$$
\mathrm{LAI}_{\text {eff }}=\lambda_{o} \text {. LAI }
$$

Onde LAI indica o valor de IAF verdadeiro obtido por métodos destrutivos diretos e o $\mathrm{LAI}_{\text {eff }}$ é o IAF efetivo obtido por métodos indiretos, considerandose uma distribuição aleatória das folhas. O valor efetivo do IAF considera ajustes no cálculo a partir do parâmetro de dispersão $\lambda o$ (NILSON, 1971; LEMEUR; BLAD, 1974), também chamado de clumping index (CHEN; BLACK, 1992; CHEN; CIHLAR, 1995, 1996).

Estudos anteriores indicaram que os valores de IAF verdadeiro são cerca de $50 \%$ a $65 \%$ maiores que os valores de IAF efetivo (JONCKHEERE et al., 2005; ZHENG; MOSKAL, 2009) e esse fato também foi observado nas pesquisas do grupo com o modelo Can-eye (SHINZATO; DUARTE; YOSHIDA, 2015).

O parâmetro de dispersão é calculado no modelo Can-Eye segundo os estudos de Lang e Yueqin (1986) e varia conforme a estrutura da planta, a distribuição das folhas na copa, o tipo e tamanho das folhas. Esse parâmetro indica a distribuição espacial das folhas na copa, sendo que o valor igual a 1 representa uma distribuição aleatória das folhas; o decréscimo dos valores a partir de 1 indica maior sobreposição das folhas na copa; para valores maiores que 1 , a copa apresenta uma distribuição mais regular das folhas (CHEN; BLACK, 1992).

\section{Modelo ENVI-met 3.1}

O ENVI-met é um modelo tridimensional para simular as interações entre superfície-vegetaçãoatmosfera para ambientes urbanos com resoluções de $0,5 \mathrm{~m}$ a $10 \mathrm{~m}$ no espaço e até $10 \mathrm{~s}$ no tempo.
Dessa forma, permite analisar, em uma perspectiva de microescala, a interação entre o desenho urbano, o solo e a atmosfera (BRUSE; FLEER, 1998; HUTTNER, 2009).

Esse modelo prognóstico está baseado nas leis de dinâmica dos fluidos e da termodinâmica. Inclui simulações para: o fluxo de ar em volta e entre os edifícios; a troca de calor e vapor de água na superfície do piso e fachadas; a turbulência local e sua taxa de dissipação; os parâmetros de troca de calor com a vegetação e dispersão de partículas poluentes. Apresenta ferramentas adicionais como o programa Leonardo 3.0 Beta para visualização e edição dos resultados gerados pelo ENVI-met (BRUSE; FLEER, 1998).

O modelo ENVI-met foi escolhido para a pesquisa devido à sua abordagem avançada sobre as interações solo-vegetação-atmosfera nas cidades. $\mathrm{O}$ ENVI-met é um dos poucos modelos que busca descrever a maior parte dos processos climáticos que agem no ambiente urbano. Em relação à vegetação, esse modelo determina a temperatura média nas folhas por meio do cálculo do balanço térmico que considera a condição climática e fisiológica da planta. O cálculo do fluxo de radiação inclui sombreamento, absorção e reemissão da radiação por outras partes da planta.

Os estudos com a versão 3.1 foram realizados logo após as medições microclimáticas; nessa época, o doutoramento da primeira autora estava em curso, em estágio avançado, quando surgiu a versão 4.0, disponibilizada publicamente em outubro de 2014. Optou-se, então, por dar continuidade ao trabalho na versão 3.1, uma vez que os novos recursos precisavam de mais tempo para serem testados e avaliados.

Esse modelo considera não apenas o efeito de sombreamento das árvores, mas também o processo fisiológico da evapotranspiração. A abertura dos estômatos é um controle vital da planta para permitir as trocas gasosas e evitar a perda excessiva de água para o ambiente. Dessa forma, quanto menor a disponibilidade de recursos como luz e água no solo, maior é a resistência dos estômatos $\left(\mathrm{r}_{\mathrm{s}}\right)$. Esse fator pode ser calculado no modelo ENVImet segundo o método de cálculo proposto por Jacobs (1994).

Assim, para se verificar o efeito da vegetação, é fundamental um correto ajuste nos dados de entrada do modelo de solo. Dessa forma, as características do tipo do solo (teor de água na saturação, na capacidade de campo, no ponto de murcha e condutividade hidráulica), os dados de temperatura do solo e umidade nas diferentes camadas são fundamentais para 0 modelo reproduzir 0 comportamento das plantas. 
Em relação ao efeito das árvores brasileiras, foram necessárias mudanças no banco de dados de vegetação do modelo (PLANTS.DAT), no que se refere aos valores do albedo e da densidade foliar. O modelo, em vez de utilizar diretamente os valores do IAF, utiliza como parâmetro para a quantidade de folhas o valor da densidade de área foliar (DAF), distribuída em dez camadas de folhas. Os valores de IAF são calculados no modelo integrando-se os valores $\mathrm{DAF}^{4}$, do inglês leaf area density (LAD) para diferentes alturas (z).

Os valores DAF, além de indicarem processos fisiológicos da planta (devido à quantidade de folhas), também indicam a atenuação da radiação solar na copa. Este fator contribui para o sombreamento e tem um efeito no conforto térmico dos pedestres, principalmente em cidades de clima tropical (CHEN; WONG, 2006).

Os valores médios de IAF efetivo obtido para os 22 pontos medidos no Trianon correspondem a IAF 2,1 $\mathrm{m}^{2} / \mathrm{m}^{2}$ (imagens hemisféricas) e IAF $2,5 \mathrm{~m}^{2} / \mathrm{m}^{2}$ (LAI-2000). O IAF efetivo descreve melhor a interceptação da radiação pela distribuição das folhas e o regime radiativo dentro e abaixo da copa.

Apesar dos valores médios obtidos com o equipamento LAI-2000 e por fotos hemisféricas serem próximos, o IAF médio medido com o equipamento LAI-2000 costuma ser superior em relação aos cálculos de pós-processamento das imagens hemisféricas feitos pelo Can-Eye, uma vez que o equipamento acaba considerando não só as folhas, mas outros elementos da vegetação como tronco, galhos, flores. Nesse caso, o modelo CanEye oferece mais recursos para a análise da imagem e o mascaramento de áreas indesejadas.

Para a calibração do ENVI-met foi considerado o valor do IAF médio de $2,5 \mathrm{~m}^{2} / \mathrm{m}^{2}$, obtido nas medições de campo com o equipamento LAI-2000 nos 22 pontos medidos no Parque Trianon. Em seguida, considerando-se as condições locais do Parque Trianon, foram estruturadas três etapas de simulações, a fim de se verificar o efeito da vegetação no microclima a partir da interação solovegetação-atmosfera no modelo.

Na primeira etapa dos estudos paramétricos foram testadas duas tipologias de árvores: uma com a copa no formato esférico e outra no formato alongado (elipse vertical), ambas com $20 \mathrm{~m}$ de altura e com os valores de IAF: $1 \mathrm{~m}^{2} / \mathrm{m}^{2}, 3 \mathrm{~m}^{2} / \mathrm{m}^{2}$ e $5 \mathrm{~m}^{2} / \mathrm{m}^{2}$. Na segunda etapa foram geradas simulações em função das alterações da velocidade dos ventos na configuração dos dados de entrada. Durante a calibração do modelo, nas etapas preliminares do estudo, foi considerada uma velocidade de $1 \mathrm{~m} / \mathrm{s}$ para se evitar problemas de instabilidade e erros de convergência dos dados.

Para estas simulações, três categorias de vegetação foram selecionadas no ENVI-met: a primeira com uma copa pouco densa (IAF $1 \mathrm{~m}^{2} / \mathrm{m}^{2}$ ), a segunda com uma copa média (IAF $3 \mathrm{~m}^{2} / \mathrm{m}^{2}$ ), ambas efetivamente medidas dentro do parque, e uma terceira copa bastante densa (IAF $5 \mathrm{~m}^{2} / \mathrm{m}^{2}$ ), para se testar na simulação, porém superior aos valores medidos.

Os modelos paramétricos das árvores tinham dois tipos de configurações: formato elipsoide e esférico (Figura 5), com distribuições de DAF máxima localizada na altura média da copa. Todas as árvores tinham $20 \mathrm{~m}$ de altura e sua copa começava a $5 \mathrm{~m}$ acima do solo, para se evitar a obstrução de fluxo de vento no nível dos pedestres. Foram construídos cenários paramétricos em que um único parâmetro era alterado por vez, mantendo-se os demais valores com a mesma configuração definida na calibração do modelo.

Figura 5 - Distribuição da DAF para diferentes formatos de copa (esférica e elíptica)
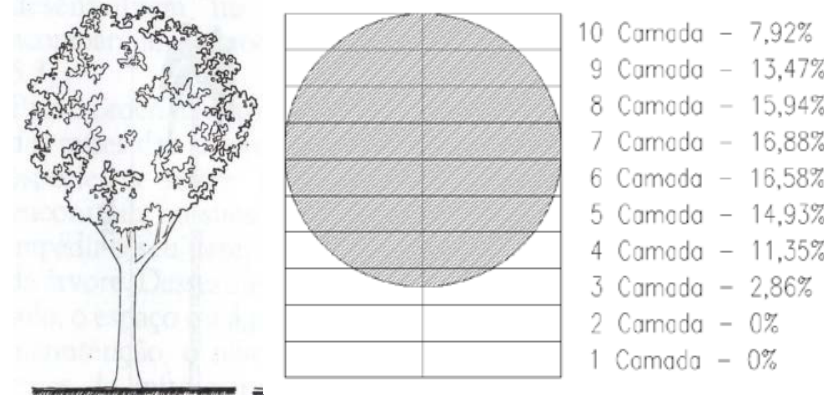

4Segundo Weiss et al. (2004): "DAF is defined as the total onesided leaf area per unit of layer volume". Dessa forma, os valores de DAF expressam um índice de densidade foliar que relaciona a área total de um dos lados das folhas pelo volume da forma geométrica da copa $\left(\mathrm{m}^{2} / \mathrm{m}^{3}\right)$. Nos processos de interação entre o dossel e a atmosfera, a quantidade de folhas e sua
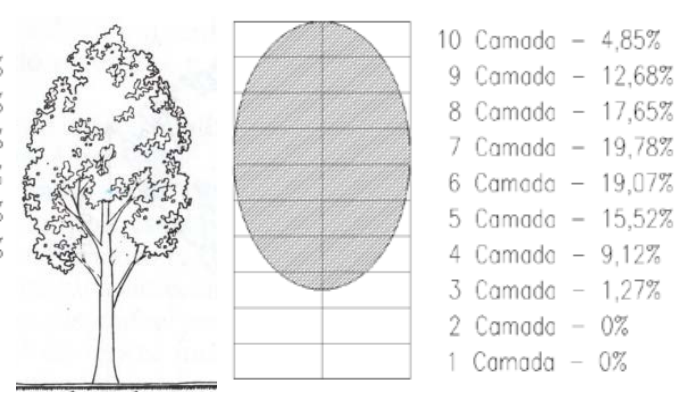

distribuição espacial dentro da copa desempenham um papel importante no efeito microclimático da vegetação. 0 cálculo do DAF depende de fatores como: dimensões da copa, altura da árvore, área foliar em relação à proj eção da copa e tamanho das folhas (LALIC; MIHAILOVIC, 2004). 


\section{Resultados e discussão \\ Processo de calibração do modelo com dados medidos e simulados}

Os dados levantados em campo foram importantes para se calibrar o modelo ENVI-met em relação às condições microclimáticas locais. Esses estudos de sensibilidade foram importantes para se investigar as principais variáveis do modelo e verificar a influência de cada parâmetro nos dados de entrada. Antes de inserir as áreas verdes, foi fundamental ajustar os dados de entrada do modelo às condições climáticas para São Paulo.

A Figura 6 mostra os resultados medidos para temperatura do ar nos dois pontos do Parque Trianon e os dados obtidos de duas estações fixas de referência, uma no Aeroporto de Congonhas (WMO 83780) e outra no IAG-USP Água Funda (WMO 83004). A estação IAG/Água Funda localiza-se dentro de um parque muito maior, mas com a estação sobre grama, sem sombreamento de árvores ou edifícios, seguindo o padrão das estações WMO, e, portanto, com perda maior de radiação de onda longa no período noturno, se comparada ao Parque Trianon.

Nesse período, os dados medidos no Parque Trianon mostram uma amplitude térmica de $10^{\circ} \mathrm{C}$ no dia $14 / 11 / 2013$ e $15{ }^{\circ} \mathrm{C}$ no dia $15 / 11 / 2013$ com a temperatura do ar chegando a $29^{\circ} \mathrm{C}$ no ponto 1 . As diferenças na temperatura do ar entre os pontos $1 \mathrm{e}$ 2 chegaram a atingir $1,9{ }^{\circ} \mathrm{C}$ no dia $15 / 11 / 2013$, às 11h. O Aeroporto de Congonhas apresentou o maior pico da temperatura do ar registrado no período $\left(31,5^{\circ} \mathrm{C}\right.$ no dia $\left.15 / 11 / 2013\right)$ às $15 \mathrm{~h}$.

Quando comparado aos parques, o Aeroporto de Congonhas é, em geral, mais quente durante o dia e mais frio durante a noite, devido ao céu desobstruído, com maior perda de radiação de onda longa no período noturno. Por outro lado, nos dois parques, especialmente no Trianon, com as duas estações meteorológicas posicionadas abaixo do dossel arbóreo, as temperaturas do ar são um pouco mais altas à noite, conforme esperado para um espaço semiconfinado e com pouca visão de céu provocada pela obstrução das copas, o que já era indicado nos estudos de Spronken-Smith e Oke (1999).

A comparação dos valores de umidade específica, calculados a partir dos dados medidos segundo
Bolton (1980), mostra as diferenças entre o conteúdo real de umidade entre os pontos, contrastando o ambiente mais seco do Aeroporto de Congonhas com os locais mais úmidos nos parques, devido ao solo natural gramado e o dossel arbóreo denso. Ambos os pontos 1 e 2 no Parque Trianon apresentaram, em média, umidade específica intermediária entre o IAG-USP Água Funda e o Aeroporto (Figura 7).

Em relação à velocidade dos ventos, o ponto 1 apresentou valores ligeiramente mais altos do que 0 ponto 2, por estar menos confinado pela vegetação, mais exposto às trocas convectivas, próximo ao portão de entrada voltado à Av. Paulista. A estação no ponto 1 registrou uma velocidade média de 0,64 $\mathrm{m} / \mathrm{s}$, enquanto o ponto 2 chegou a $0,54 \mathrm{~m} / \mathrm{s}$. No ponto 1 houve predominância da direção dos ventos no sentido NE e NO, sendo que a NE está localizada a entrada do Parque pela Av. Paulista. No ponto 2, no centro do parque, a direção do vento variou significativamente, sem predominância clara.

Para o registro da temperatura do solo, um sensor foi posicionado até uma profundidade de $4 \mathrm{~cm}$ em relação à superfície, nos dois pontos de medição. Houve uma significativa diferença nas temperaturas medidas no ponto 1 , no intervalo entre $8 \mathrm{~h}$ e $17 \mathrm{~h}$, chegando a apresentar temperatura de até $35{ }^{\circ} \mathrm{C}$ (14h do dia 15/11/2013), enquanto as temperaturas de solo na parte central do parque variaram entre 18 ${ }^{\circ} \mathrm{C}$ e $27^{\circ} \mathrm{C}$. Verifica-se, assim, que o sombreamento das copas das árvores mais densas foi determinante para se evitar o aquecimento do solo no ponto 2.

Os dados de temperatura radiante média (TRM) apresentados foram calculados segundo a norma ISO 7726 (INTERNATIONAL..., 1998), com a equação por convecção forçada. A Figura 8 mostra o resultado dos valores calculados para temperatura média radiante dos pontos 1 e 2, indicando diferenças no período das $8 \mathrm{~h}$ às $14 \mathrm{~h} 30$ entre as duas estações, chegando a $5{ }^{\circ} \mathrm{C}$ de diferença às $14 \mathrm{~h}$ do dia16/11/2013. Além do ponto 1 sofrer maiores flutuações na velocidade do vento, por estar mais exposto às trocas convectivas próximo à entrada do parque, diferenças no tipo do piso (pedriscos no ponto 1 e solo gramado no ponto 2) e, principalmente, a densidade foliar também influenciaram a TRM, alterando a temperatura de globo registrada nos dois pontos, sendo que o dossel no ponto 2 é mais denso, reduzindo a passagem da radiação direta e difusa em comparação ao ponto 1 . 
Figura 6 - Temperatura do ar registrada no Trianon (pontos 1 e 2), no Aeroporto de Congonhas (WMO 83780) e no IAG-USP Água Funda (WMO 83004), em novembro de 2013 LST - Local Standard Time, com a correção do horário de verão nos dados medidos em novembro de 2013

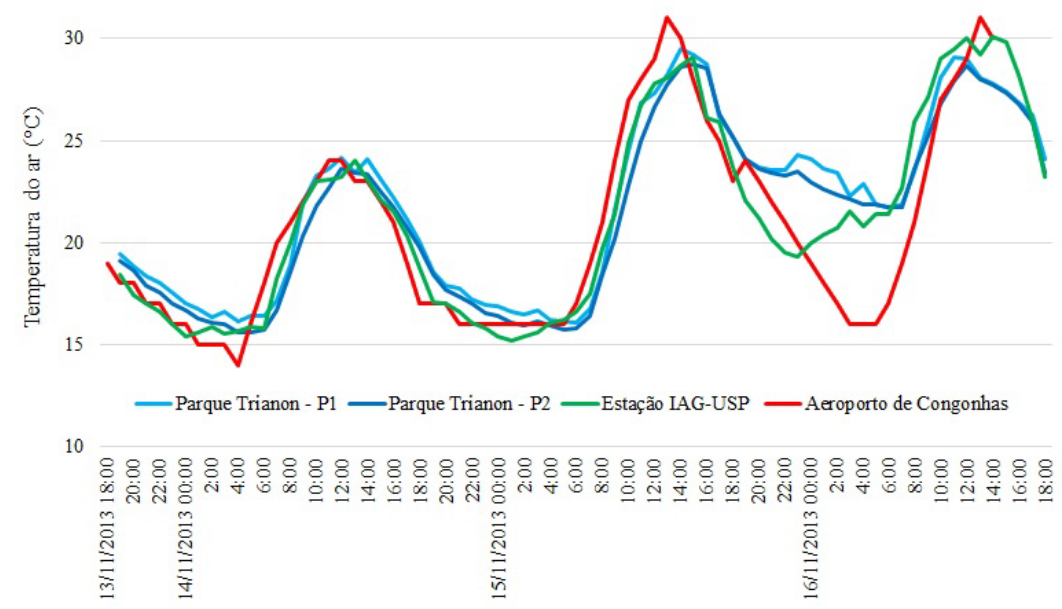

Figura 7 - Umidade específica calculada com base nos dados registrados no Trianon (pontos 1 e 2), no Aeroporto de Congonhas (WMO 83780) e no IAG/USP Água Funda (WMO 83004), em novembro de 2013 Local Standard Time (LST)

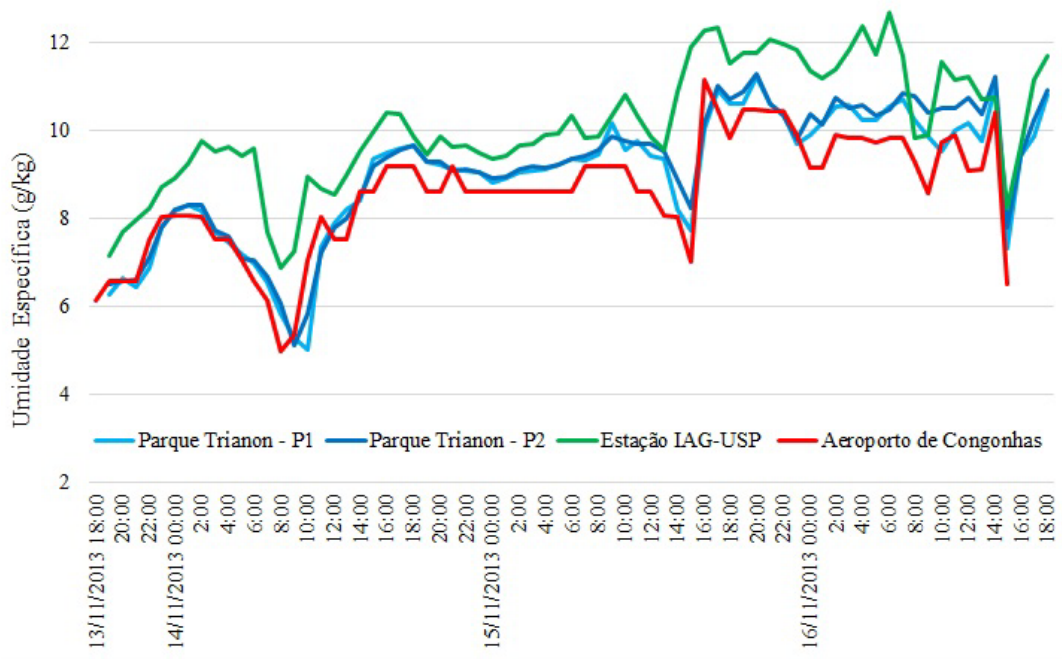

Dessa forma, a curva da TRM gerada para o ponto 2 (centro do parque) segue um perfil com poucas oscilações, enquanto no ponto 1 (entrada do parque) os dados apresentam maiores variações, principalmente durante o dia. Os valores da TRM não foram calculados para a estação IAG-USP Água Funda e para o Aeroporto de Congonhas porque as estações não têm termômetro de globo.

Observou-se que para as condições climáticas locais é fundamental o processo de calibração do modelo, com ajustes nos dados de entrada das principais variáveis microclimáticas. $\mathrm{O}$ processo de calibração demandou ajustes por testes de sensibilidade das seguintes variáveis: velocidade do vento, tamanho da grade de aninhamento, temperatura inicial e umidade relativa do ar, radiação solar e cobertura de nuvens, a fim de se atingir os valores de temperatura do ar simulados no modelo similares aos dados medidos. O processo de calibração foi realizado segundo os estudos de Assis, Sirqueira e Bamerg (2013) e Francisco (2012). Em ambos os estudos, foi indicado que o processo de calibração precisa ser feito durante um período de pelo menos $24 \mathrm{~h}$.

Os dados de entrada para as simulações estão apresentados na Tabela 2, e a modelagem na Figura 9. A radiação solar, que é calculada pelo modelo em função da latitude, foi ajustada de acordo com a radiação medida para 0,4 octas na cobertura de nuvens (fração de nuvens médias). $\mathrm{O}$ fator de ajuste para a radiação solar foi de 0,9 . $O$ ajuste da radiação considerou os valores médios para radiação global 
e difusa registrados para o mês de novembro, segundo dados do Laboratório de Micrometeorologia (LabMicro) ${ }^{5}$. Na versão 3.1 é possível visualizar as curvas da radiação solar (global, direta e difusa) de acordo com a configuração dos dados de entrada e ajustá-las por meio do fator de ajuste para radiação (solar adjust). Os dados de cobertura de nuvens contribuíram positivamente para o ajuste dos dados da radiação difusa.

Os únicos dados climáticos adicionais (não derivados de medições locais) foram a umidade específica a $2.500 \mathrm{~m}$ de altitude e a umidade do solo. A umidade específica a $2.500 \mathrm{~m}$ é obtida em sondagens feitas por balões atmosféricos na estação meteorológica do Aeroporto Campo de Marte (WMO 83779) a cerca de 3,3 km a norte do local, e disponibilizada publicamente pela Universidade de Wyoming ${ }^{6}$. A temperatura do solo para a camada superior foi medida in loco utilizando-se o sensor de temperatura e umidade Campbell e os demais dados do solo (teor de água no ponto de murcha e no ponto de saturação) foram estimados com base em estudos ${ }^{7}$ utilizando-se o modelo Simple Biosphere Model (SiB2).

Figura 8 - Temperatura radiante média para as estações ponto 1 e 2 - dados entre os dias 13 e 16 de novembro de 2013

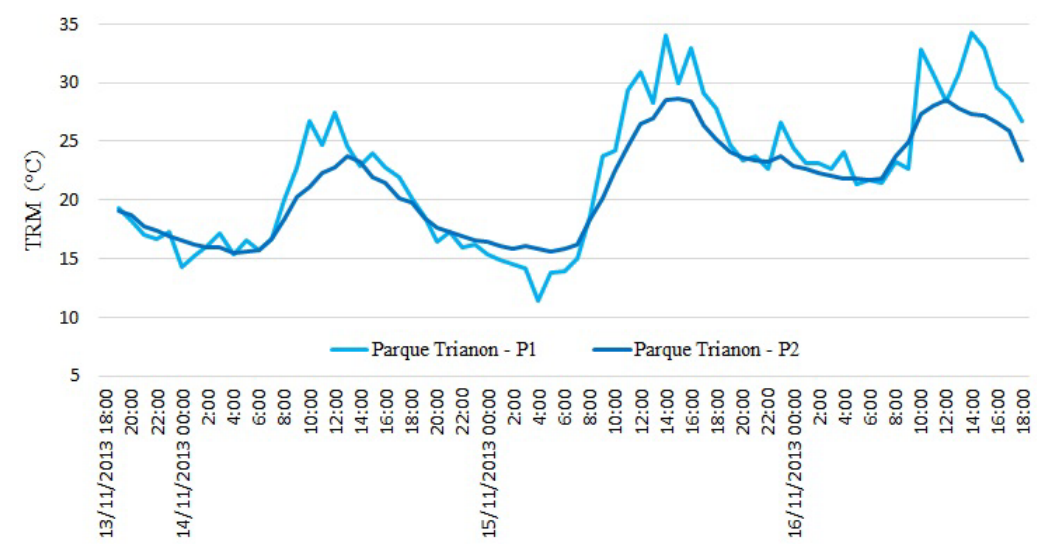

Tabela 2 - Configuração dos dados de entrada no ENVI-met

\begin{tabular}{l|l}
\hline Data do início da simulação & $13 / 11 / 2013$ \\
\hline Velocidade do vento a 10 m (m/s) & 1,0 \\
\hline Direção do vento (0:N..90:E..180:S..270:W..) & 250 \\
\hline Temperatura potencial inicial [K] & $291\left(18^{\circ} \mathrm{C}\right)$ \\
\hline Umidade específica a 2.500 m (g Water/kg air) & 11,2 \\
\hline Umidade relativa a 2 m [\%] & 52,5 \\
\hline Temperatura inicial do solo na primeira camada $(0-20 \mathrm{~cm})(\mathrm{K})$ & $291,5\left(18,5^{\circ} \mathrm{C}\right)$ \\
\hline Umidade relativa do solo na primeira camada $(0-20 \mathrm{~cm})$ & 40 \\
\hline
\end{tabular}

${ }^{5}$ Laboratório de Micrometeorologia do Instituto de Astronomia, Geofísica e Ciências Atmosféricas (IAG USP), dados da estação meteorológica na Plataforma do IAG no Campus da USP. Disponível em: «ttp:// www.iag. usp. br/meteo/labmicro/ Data/Graficos/SP/ >. Acesso em: 15 jun. 2017

${ }^{6}$ Disponível em: «ttp:// weather.uwyo. edu/ upperair/ sounding.html>. Acesso em: 15 jan. 2017.

${ }^{7}$ Dados estimados e gentilmente cedidos pelo Prof. Dr. Humberto Ribeiro da Rocha do Laboratório de Clima e Biosfera, do IAG da USP, para o mesmo período medido. 
Figura 9 - Cenário base no modelo ENVI-met v.3.1

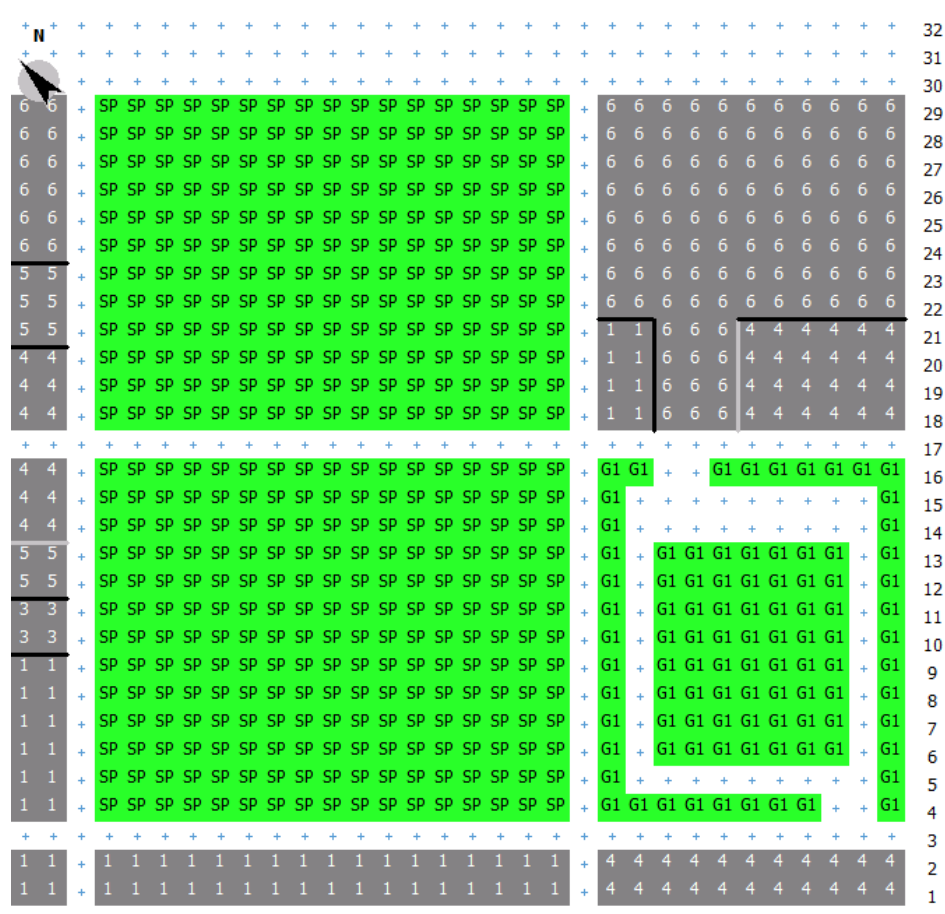

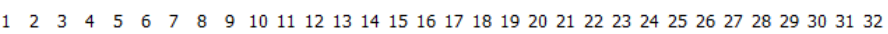

Inicialmente um cenário base foi criado, formado pelas duas quadras ocupadas pelo Parque Trianon, com 170 m x 120 m (20.400 m²) cada uma, e mais cinco quadras ao redor do parque. A área total de modelagem foi de $102.400 \mathrm{~m}^{2}$ com uma grade de 32 x 32 células e cada célula com dimensões de $10 \mathrm{~m}$ $\mathrm{x} 10 \mathrm{~m}$.

A Figura 10 mostra o resultado da simulação extraído a partir do ponto 2, localizado na área central do parque, no centro da modelagem e com resultados mais precisos em relação às células próximas às bordas do modelo.

Os dados medidos no dia 13 de novembro, adotados para a calibração deste trabalho, apresentam variação de $17^{\circ} \mathrm{C}$ a $24^{\circ} \mathrm{C}$, muito próxima dos dados médios para o mês de novembro $\left(18{ }^{\circ} \mathrm{C}\right.$ a $\left.25^{\circ} \mathrm{C}\right)$ no período 1996-2015, calculados pelo Grupo de Micrometeorologia do IAG da USP.

O modelo ENVI-met 3.1 permite simular vários dias seguidos e se retroalimenta a partir do segundo dia de simulação com o resultado dos dados gerados no dia anterior. No entanto, na versão 3.1, não existe a possibilidade de correção dos dados microclimáticos durante a simulação. Assim, priorizou-se o ajuste do modelo com os dados medidos no primeiro dia, por este se apresentar mais estável em relação aos dois dias posteriores.

Comparando-se as medições de campo com dados do primeiro dia de simulação, e aplicando-se alguns testes estatíticos, verificou-se que, para a temperatura do ar, o valor do Root Mean Square Error (RMSE) é de $1,52^{\circ} \mathrm{C}$ e Mean Absolute Error (MAE) é de $1,30^{\circ} \mathrm{C}$.

Nos estudos de Minella e Krüger (2017), realizouse o processo de calibração e testes estatísticos em relação aos resultados medidos e simulados no modelo ENVI-met. Importante ressaltar que apesar da estimativa do erro quadrático obtida nesse trabalho ter sido menor, de $0,55{ }^{\circ} \mathrm{C}$, o período medido foi curto, das $10 \mathrm{~h}$ às $15 \mathrm{~h}$, o que não permite verificar o comportamento do modelo nos demais horários, principalmente no período noturno, quando as diferenças são geralmente maiores.

Os erros quadrático e absoluto, apesar de um pouco maiores que $1{ }^{\circ} \mathrm{C}$, podem ser considerados aceitáveis, uma vez que a calibração feita para este trabalho considerou um período de 24h, considerado mínimo por Assis, Sirqueira e Bamberg (2013) e Francisco (2012), sendo que o melhor ajuste dos resultados ocorreu durante o dia. No período noturno, as diferenças são um pouco maiores e existe uma tendência do modelo em apresentar temperaturas do ar mais elevadas em relação aos dados medidos. Isso ocorre porque o modelo ENVI-met deixa de realizar a evapotranspiração logo após o pôr do sol pelo fechamento imediato dos estômatos. Numa situação real esse fechamento dos estômatos aconteceria de uma forma mais gradual. 
Figura 10 - Resultado da calibração entre dados medidos e simulados para os dias 13 a 15 de novembro de 2013

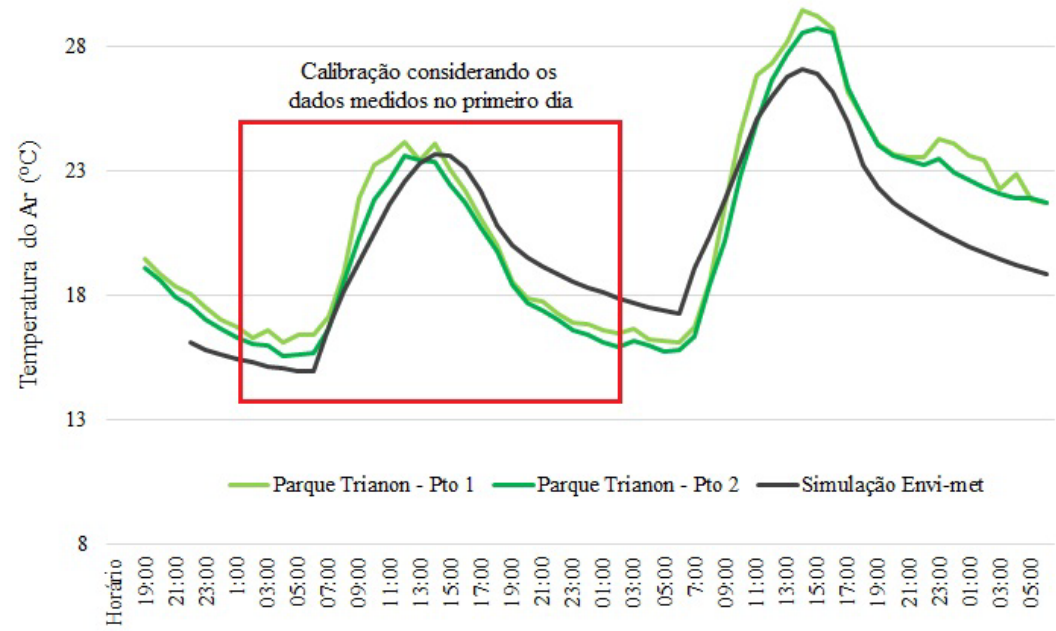

O fator index of agreement (d) desenvolvido por Willmott (1981) também foi aplicado, conforme a Equação 2:

$d=1-\left[\frac{\sum_{i=1}^{n}\left(S_{i}-M_{i}\right)^{2}}{\sum_{i=1}^{n}\left(\left|S_{i}-\bar{M}\right|+\left|M_{i}-\bar{M}\right|\right)^{2}}\right]$

Onde:

$S_{i}=$ dado simulado;

$M_{i}=$ dado medido em campo; e

$\bar{M}=$ valor médio das medições de campo.

O valor calculado do index of agreement foi de 0,94, indicando que os resultados do ENVI-met se aproximam bastante das medições realizadas em campo. Sendo assim, os dados microclimáticos da calibração do modelo para o primeiro dia foram considerados nas simulações paramétricas na etapa seguinte.

\section{Resultado das simulações paramétricas com vegetação}

Etapa 1: Nessa etapa foram simulados os efeitos da temperatura do ar e da temperatura de superfície com variações nas copas das árvores com IAF 1 $\mathrm{m}^{2} / \mathrm{m}^{2}, 3 \mathrm{~m}^{2} / \mathrm{m}^{2}$ e $5 \mathrm{~m}^{2} / \mathrm{m}^{2}$ e no formato do dossel (esférica e elíptica vertical).

Com base nos resultados da simulação, a obstrução da radiação pelas árvores varia de acordo com os valores de IAF e a tipologia da copa. Por exemplo, para uma árvore com IAF $5 \mathrm{~m}^{2} / \mathrm{m}^{2}$, a porcentagem de radiação solar direta que chega ao solo é cerca de $5 \%$ do total da radiação incidente.

Nos resultados para temperatura do ar, percebe-se que para um mesmo valor de IAF e apenas variando o formato da copa, a temperatura do ar a 1,5 m acima do solo para a copa elíptica vertical é em média $0,3^{\circ} \mathrm{C}$ menor do que para copa esférica. Essa diferença é pequena, e acontece em função do agrupamento das folhas na copa. Observa-se também uma redução máxima de $0,9{ }^{\circ} \mathrm{C}$ ao se comparar o valor simulado abaixo da copa elíptica de IAF $5 \mathrm{~m}^{2} / \mathrm{m}^{2}$ em relação à temperatura do ar no receptor colocado na rua, sobre o asfalto (Figura 11a).

O efeito do sombreamento das árvores na temperatura da superfície é apresentado na Figura 11b. A temperatura superficial abaixo do dossel das árvores de copa elíptica variou de $39,0^{\circ} \mathrm{C}$ (IAF 1 $\mathrm{m}^{2} / \mathrm{m}^{2}$ ) a $49,0^{\circ} \mathrm{C}$ (IAF $5 \mathrm{~m}^{2} / \mathrm{m}^{2}$ ), e para as árvores de copa esférica, de 39,5 (IAF $1 \mathrm{~m}^{2} / \mathrm{m}^{2}$ ) a $49,4^{\circ} \mathrm{C}$ (IAF $5 \mathrm{~m}^{2} / \mathrm{m}^{2}$ ). Comparando-se a temperatura superficial simulada pelo receptor posicionado na rua e na vegetação, percebe-se uma diferença máxima de $19,0^{\circ} \mathrm{C}$ entre o piso de asfalto exposto e na superfície abaixo do dossel para copa elíptica de IAF $5 \mathrm{~m}^{2} / \mathrm{m}^{2}$.

Para ambas as tipologias, a umidade específica sob o dossel variou muito pouco, de $11,0 \mathrm{~g} / \mathrm{kg}$ (IAF 1 $\mathrm{m}^{2} / \mathrm{m}^{2}$ ) para $11,1 \mathrm{~g} / \mathrm{kg}$ (IAF $5 \mathrm{~m}^{2} / \mathrm{m}^{2}$ ) e o menor valor foi obtido acima do asfalto com $10,9 \mathrm{~g} / \mathrm{kg}$.

Com base nos resultados, o índice TEP, desenvolvido para espaços urbanos exteriores em climas subtropicais (MONTEIRO; ALUCCI, 2012), foi aplicado de acordo com a Equação 3:

$\mathrm{TEP}=-3,777+0,4828$. Ta +

0,5172. Tmrt + 0,0802. Rh $-2,322 . \mathrm{V}$

Eq. 3

Onde:

$\mathrm{Ta}=$ temperatura do ar em ${ }^{\circ} \mathrm{C}$;

Tmrt = temperatura média radiante em ${ }^{\circ} \mathrm{C}$;

$\mathrm{Rh}=$ umidade relativa do ar em \%; e 
$\mathrm{v}=$ velocidade do vento em $\mathrm{m} / \mathrm{s}$.

A Tabela 3 mostra o valor das variáveis microclimáticas para o cálculo da TEP, considerando-se os resultados simulados no ENVImet para grupo de árvores com copas elípticas para o dia 13 de novembro às $15 \mathrm{~h}$. Observa-se que apesar da pequena redução de até $0,9^{\circ} \mathrm{C}$ na temperatura ar, comparando a condição abaixo das árvores densas (IAF $5 \mathrm{~m}^{2} / \mathrm{m}^{2}$ ) e na rua, para a temperatura média radiante as diferenças são significativas e podem chegar a $16,5^{\circ} \mathrm{C}$ para as mesmas condições. Assim, entre todas as variáveis medidas e simuladas, os valores da temperatura média radiante são os mais impactados na presença da vegetação arbórea, influenciando diretamente o índice de conforto térmico.

Dessa forma, os resultados da TEP indicaram uma sensação térmica entre $23,8{ }^{\circ} \mathrm{C}$ e $25,01{ }^{\circ} \mathrm{C}$ das pessoas no parque (sensação de neutralidade pelas faixas interpretativas da TEP), sentida abaixo de copas com IAF entre $1 \mathrm{~m}^{2} / \mathrm{m}^{2}$ e $5 \mathrm{~m}^{2} / \mathrm{m}^{2}$, para o mês de novembro às $15 \mathrm{~h}$, enquanto a sensação térmica nas vias com asfalto e sem sombreamento ficou em $31,5{ }^{\circ} \mathrm{C}$ (sensação de pouco calor pela TEP), considerando-se uma temperatura do ar de $28,5{ }^{\circ} \mathrm{C}$ e velocidade dos ventos de $1 \mathrm{~m} / \mathrm{s}$.

Figura 11 - (a) Resultados da simulação para a temperatura do ar comparando-se diferentes tipologias do dossel e valores de IAF às $15 \mathrm{~h}$ (b) Resultados da simulação para a temperatura de superfície comparando-se diferentes tipologias de dossel e valores de IAF às $15 \mathrm{~h}$

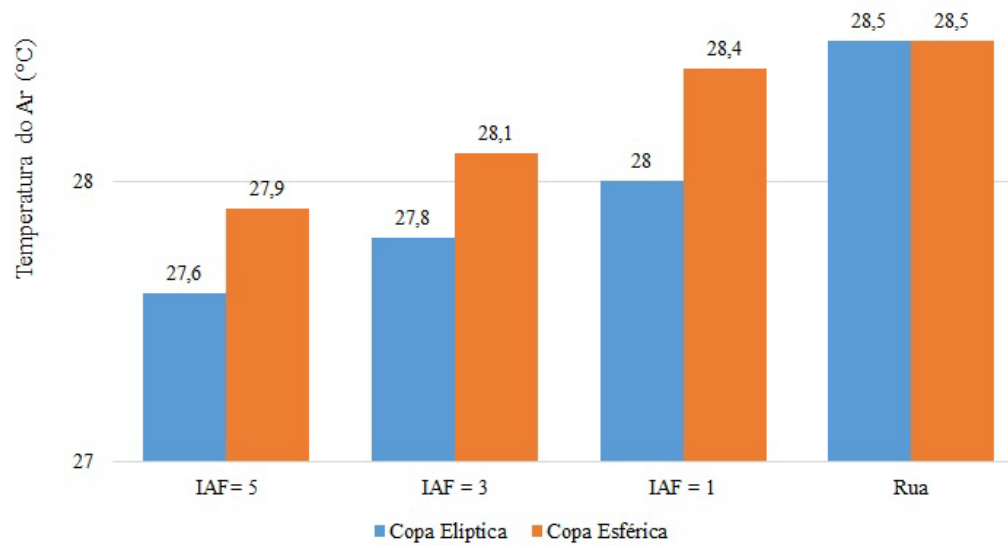

(a)

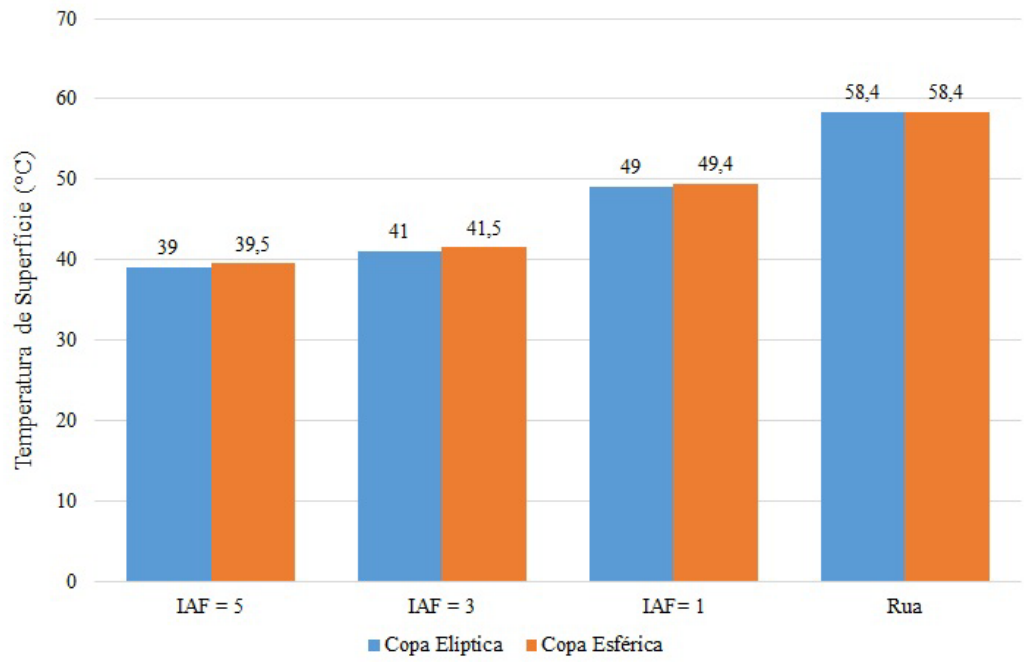

(b) 
Tabela 3 - Resultados da TEP para os dados simulados no ENVI-met - 15h

\begin{tabular}{l|c|c|c|c|c|l}
\multicolumn{1}{c|}{ Cenário } & Ta $\left({ }^{\circ} \mathbf{C}\right)$ & TRM $\left({ }^{\circ} \mathbf{C}\right)$ & Rh (\%) & $\mathbf{v ~ ( m / s ) ~}$ & TEP & $\begin{array}{c}\text { Faixas } \\
\text { Interpretativas }\end{array}$ \\
\hline Rua no entorno do parque & 28,5 & 39,0 & 45,5 & 1,0 & 31,5 & Pouco calor \\
\hline $\begin{array}{l}\text { copas elípticas (IAF 1 } \\
\mathrm{m}^{2} / \mathrm{m}^{2} \text { ) }\end{array}$ & 28,0 & 24,9 & 59,3 & 1,0 & 25,1 & Neutralidade \\
\hline $\begin{array}{l}\text { copas elípticas (IAF 3 } \\
\mathrm{m}^{2} / \mathrm{m}^{2} \text { ) }\end{array}$ & 27,8 & 24,0 & 60,0 & 1,0 & 24,5 & Neutralidade \\
\hline $\begin{array}{l}\text { copas elípticas (IAF 5 } \\
\mathrm{m}^{2} / \mathrm{m}^{2} \text { ) }\end{array}$ & 27,6 & 22,5 & 61,4 & 1,0 & 23,8 & Neutralidade \\
\hline
\end{tabular}

Os resultados estão de acordo com os estudos de Coutts et al. (2012), Shashua-Bar, Pearlmutter e Erell (2010) e Santamouris (2001), mencionados anteriormente, em que o desconforto pelo calor durante o dia é algo que pode e deve ser amenizado pela vegetação, principalmente em climas tropicais, mesmo quando o seu efeito na temperatura do ar é limitado, já que a diferença mais expressiva acontece na temperatura radiante média, influenciada em parte pelo piso e, principalmente, pelo dossel. Conforme os estudos de Labaki et al. (2009), no caso dos parques urbanos, os agrupamentos arbóreos exercem influência em uma escala maior do que uma única árvore. Ou seja, a disposição de elementos arbóreos pode aumentar a capacidade de redução da temperatura do ar e a atenuação da radiação incidente, bem como intensificar as sensações de conforto térmico ao usuário em um determinado raio.

Etapa 2: Nessa etapa foram comparadas as seguintes tipologias de árvores: copas esféricas e copas elípticas com IAF $1 \mathrm{~m}^{2} / \mathrm{m}^{2}, 3 \mathrm{~m}^{2} / \mathrm{m}^{2}$ e $5 \mathrm{~m}^{2} / \mathrm{m}^{2}$ em relação à variação da velocidade do vento, o que altera o DAF, conforme Figura 5. Assim, as simulações feitas com as duas tipologias de copas (esféricas e elípticas) tiveram os resultados apresentados na Figura 12a, em que a redução máxima da velocidade inicial de $1 \mathrm{~m} / \mathrm{s}$ foi para 0,5 m/s (50\%) ao passar pelo meio da copa esférica ( $\mathrm{h}=13 \mathrm{~m}$ ). O efeito da copa elíptica sobre o vento foi menor do que o da copa esférica, tendo em vista a variação do DAF e do diâmetro das copas, sendo $15 \mathrm{~m}$ para a copa esférica e $10 \mathrm{~m}$ para a copa elíptica.

As Figuras 13a e 13b mostram a porcentagem de redução do vento ao passar por diferentes tipologias de copa considerando-se uma velocidade do vento inicial de $1,0 \mathrm{~m} / \mathrm{s}, 2,0 \mathrm{~m} / \mathrm{s}$ e 4,0 m/s. Os resultados mostram que para copas esféricas, a velocidade do vento de $1,0 \mathrm{~m} / \mathrm{s}$ pode chegar a uma redução de $40 \%$ para IAF 5; 36\% para IAF 3; e 20\% para IAF 1 $\mathrm{m}^{2} / \mathrm{m}^{2}$. Em copas elípticas, para a mesma velocidade de vento de $1,0 \mathrm{~m} / \mathrm{s}$, após passar pela copa, a velocidade pode ser reduzida em até $39 \%$, $34 \%$ e $18 \%$ para os valores de IAF $1 \mathrm{~m}^{2} / \mathrm{m}^{2}, 3 \mathrm{~m}^{2} / \mathrm{m}^{2}$ e $5 \mathrm{~m}^{2} / \mathrm{m}^{2}$, respectivamente. As diferenças nos resultados são devidas à variação do DAF e do diâmetro da copa.

\section{Conclusão}

Dentre todas as variáveis medidas e simuladas, a temperatura radiante média é a mais impactada sob o dossel da vegetação arbórea, o que influencia diretamente o conforto térmico, além da influência da umidade do ar. A TRM é afetada principalmente pelas características do dossel e do solo, e o efeito do sombreamento depende não só do formato da copa, mas também da forma como as folhas estão agrupadas e distribuídas, representada pelo DAF das árvores.

O sombreamento provocado pelas copas influencia diretamente as temperaturas superficiais logo abaixo do dossel, que por sua vez também vão afetar a temperatura radiante média. Na área de estudo, verificou-se que no sombreamento pelas copas houve uma variação da temperatura superficial abaixo do dossel das árvores de copas elípticas entre $39{ }^{\circ} \mathrm{C}$ (IAF $1 \mathrm{~m}^{2} / \mathrm{m}^{2}$ ) e $49{ }^{\circ} \mathrm{C}\left(\operatorname{IAF} 5 \mathrm{~m}^{2} / \mathrm{m}^{2}\right.$ ), variação próxima dos resultados abaixo do dossel para árvores com copas esféricas entre $39,5^{\circ} \mathrm{C}$ (IAF $1 \mathrm{~m}^{2} / \mathrm{m}^{2}$ ) e $49,4^{\circ} \mathrm{C}$ (IAF $5 \mathrm{~m}^{2} / \mathrm{m}^{2}$ ).

Comparando-se os resultados simulados da temperatura superficial na área da rua e no parque, observa-se uma diferença de $17,4^{\circ} \mathrm{C}$ entre o piso de asfalto exposto e o solo abaixo do dossel de IAF 3 $\mathrm{m}^{2} / \mathrm{m}^{2}$ para copa elíptica, considerando-se uma velocidade dos ventos de $1 \mathrm{~m} / \mathrm{s}$. 
Figura 12 - (a) Perfil da velocidade do vento para copa elipsoide vertical; e (b) Perfil da velocidade do vento para copa esférica

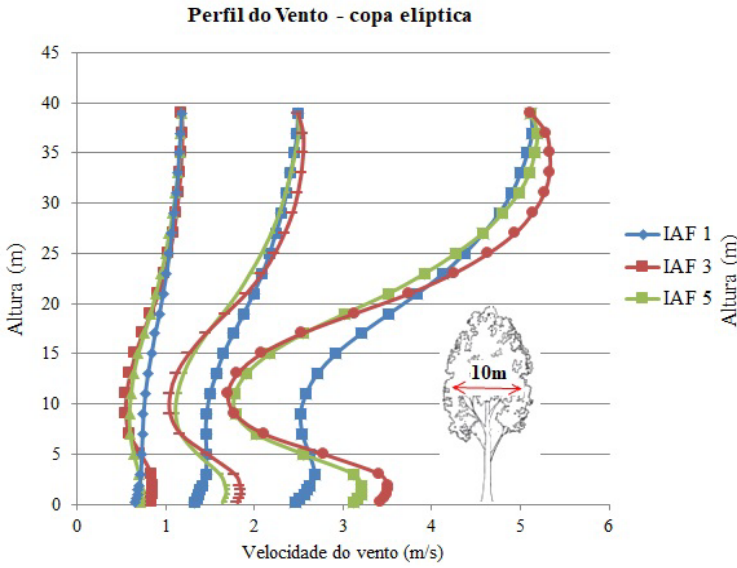

(a)

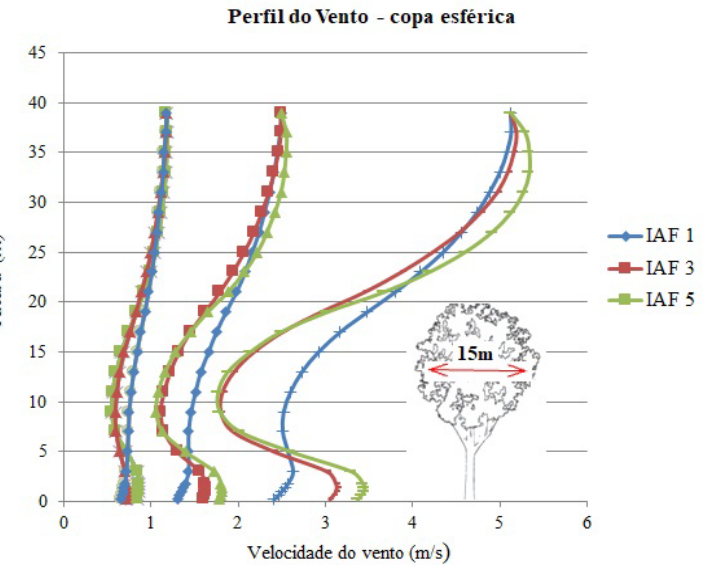

(b)

Figura 13 - (a) Redução da velocidade do vento pela copa esférica a 13 m acima do solo; (b) Redução da velocidade do vento pela copa elíptica a $13 \mathrm{~m}$ acima do solo

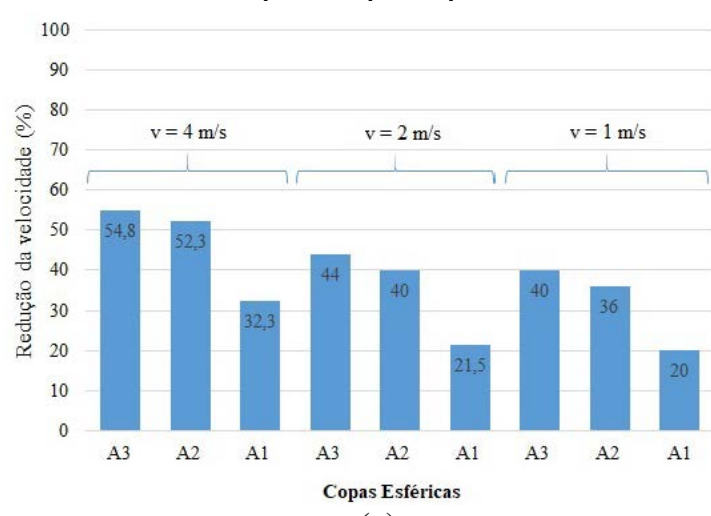

(a)

Na aplicação do índice de conforto TEP, para um IAF $3 \mathrm{~m}^{2} / \mathrm{m}^{2}$, valor este medido efetivamente dentro do parque, foi possível observar que mesmo uma redução de apenas $0,7^{\circ} \mathrm{C}$ na temperatura do ar com relação à rua no entorno, combinada com uma diferença de $15,0^{\circ} \mathrm{C}$ na temperatura radiante média, pode representar uma redução de até $7,0{ }^{\circ} \mathrm{C}$ na temperatura equivalente percebida, mesmo com uma diminuição de $34 \%$ na velocidade do vento, contribuindo para a melhoria das condições de conforto térmico dentro do parque.

\section{Referências}

ASSIS, E. S.; SIRQUEIRA, C. A.; BAMBERG, A. M. Influência da Vegetação no Microclima em Ambiente Simulado Controlado. In: ENCONTRO NACIONAL DE CONFORTO NO AMBIENTE CONSTRUÍDO, 12., Brasília, 2013. Anais... Brasília: ANTAC/UnB, 2013.

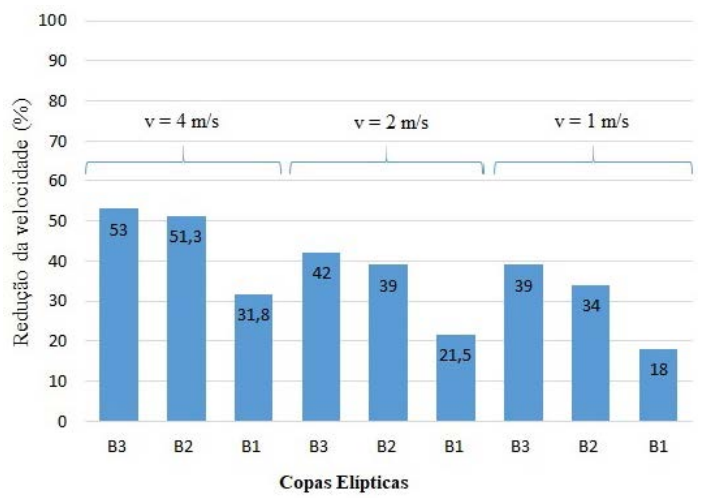

(b)

BOLTON, D. The Computation of Equivalent Potential Temperature. In: AMERICAN METEOROLOGICAL SOCIETY. Monthly Weather Review, v. 108, p. 1046-1053, 1980.

BOWLER, D. et al. Urban Greening to Cool Towns and Cities: a systematic review of the empirical evidence. Landscape and Urban Planning, v. 97, p. 147-155, 2010.

BREDA, N. J. J. Ground-Based Measurements of Leaf Area Index: a review of methods, instruments and current controversies. Journal of

Experimental Botany, v. 54, p. 2403-2417, 2003.

BRUSE, M.; FLEER, H. Simulating SurfacePlant-Air Interactions Inside Urban Environments With a Three-Dimensional Numerical Model.

Environmental Software and Modelling, v. 13, p. 373-384, 1998.

CHEN, J. M.; BLACK, T. A. Defining Leaf Area Index For Non-Flat Leaves. Plant, Cell and Environment v. 15, p. 421-429, 1992. 
CHEN, J. M.; CIHLAR, J. Quantifying the Effect of Canopy Architecture on Optical Measurements of Leaf Area Index Using Two Gap Size Analysis Methods. IEEE Transactions on Geosciences and Remote Sensing, v. 33, p. 777-787, 1995.

CHEN, J. M.; CIHLAR, J. Retrieving Leaf Area Index of Boreal Conifer Forests Using Landsat TM Images. Remote Sensing of Environment, v. 55, p. 153-162, 1996.

CHEN, Y.; WONG, N. H. Thermal Benefits of the City parks. Energy and Buildings, v. 38, p. 105120, 2006.

CHOW, W.; ROW, M. Temporal Dynamics of the Urban Heat Island in Singapore. International Journal of Climatology, v. 26, p. 2243-2260, 2006.

COUTTS, A. et al. Watering our Cities: the capacity for water sensitive urban design to support urban cooling and improve human thermal comfort ibn the Australian context. Progress in Physical Geography, v. 37, p. 2-28, 2012.

DIMOUDI, A.; NIKOLOPOULOU, $\mathrm{M}$. Vegetation in the Urban Environment: microclimatic analysis and benefits. Energy and Buildings, v. 35, n. 1, p. 69-76, 2003.

EMMANUEL, R; JOHANSSON, E. The Influence of Urban Design on Outdoor Thermal Comfort in the Hot, Humid City of Colombo, Sri Lanka. International journal of biometeorology, v. 51, p. 119-133, 2006.

EMPLASA. [Ortophoto digital 1:5000]. 2007. Disponível em:

$<$ http://www.cesadweb.fau.usp.br>. Acesso em: 07 jan. 2018.

FRANCISCO, R. C. A.Clima Urbano: um estudo aplicado a Belo Horizonte. Belo Horizonte, 2012. Dissertação (Mestrado em Ambiente Construído e Patrimônio Sustentável) - Escola de Engenharia, Universidade Federal de Minas Gerais, Belo Horizonte, 2012.

GIVONI, B. Climate Considerations in Urban and Building Design. New York: John Wiley \& Sons, 1998.

HUTTNER, S. Further Development and Application of the 3D Microclimate Simulation ENVI-met. Mainz, 2009. Tese (Doutorado em Geografia) - Johannes Gutenberg UniversitatMainz, Mainz, 2009.

INTERNATIONAL ORGANIZATION FOR STANDARDIZATION. ISO 7726: ergonomics of the thermal environment: instruments for measuring physical quantities. Genebra, 1998.
JACOBS, C. M. J. Direct Impact of Atmospheric $\mathrm{CO}_{2}$ Enrichment on Regional Transpiration. Wageningen, 1994. Tese (Doutorando) Wageningen Agricultural University, Netherland, 1994.

JONCKHEERE, E. et al. Assessment of Automatic Gap Fraction Estimation of Forests from Digital Hemispherical Photography. Agricultural and Forest Meteorology, v. 132, p. 96-114, 2005.

LABAKI, L. C. et al. Vegetação e Conforto Térmico em Espaços Urbanos Abertos. Fórum Patrimônio: Ambiente Construído e Patrimônio Sustentável, 2009.

LALIC, B.; MIHAILOVIC, D. T. An Empirical Relation Describing Leaf-Area density Inside the Forest for Environmental Modelling. Journal of Applied Meteorology, v. 7, p. 641-645, 2004.

LANG, A. R. G.; YUEQIN, X. Estimation of Leaf Area Index From Transmission of Direct Sunlight in Discontinuous Canopies. Agricultural and Forest Meteorology, v. 37, p. 229-243, 1986.

LEMEUR, R.; BLAD, B. L. A Critical Review of Light Models for Estimating the Shortwave Radiation Regime of Plant Canopies. Agricultural Meteorology, v. 14, p. 255-286, 1974.

\section{LI-COR. LAI-2000 Plant Canopy Analyser:} instruction manual. Lincoln: Li-cor Inc., 1992.

MATHEUS, C. et al. Desempenho Térmico de Envoltórias Vegetada Sem Edificações no Sudeste Brasileiro. Ambiente Construído, Porto Alegre, v. 16, n. 1, p. 71-81, jan./mar. 2016.

MINELLA, F. C. O.; KRÜGER, E. L. Proposição do Índice “Fração Vegetada” e Sua Relação Com Alterações na Temperatura do Ar e no Conforto Térmico no Período Diurno e em Situação de Verão Para Curitiba. Ambiente Construído, Porto Alegre, v. 17, n. 1, p. 353-371, jan./mar. 2017.

MONTEIRO, L. M.; ALUCCI, M. P. Modelo Adaptativo de Conforto Para Avaliação in loco de Espaços Urbanos Abertos. Ambiente Construído, Porto Alegre, v. 12, n. 1, p. 61-79, jan./mar. 2012.

NILSON, T. A Theoretical Analysis of the Frequency of Gaps in Plant Stands. Agricultural Meteorology, v. 8, p. 25-38, 1971.

OKE, T. R. Boundary Layer Climates. $2^{\text {nd }}$. ed. London: Routledge and John Wiley \& Son, 1978.

OKE, T. R. The Micrometeorology of the Urban Forest. Philosophical Transactions of the Royal Society of London, v. 324, n. 1223, p. 335-348, 1989. 
ONG, B. L. Green Plot Ratio: an ecological measure for architecture and urban planning. Landscape and Urban Planning, v. 63, p. 197211, 2002.

\section{ROSS, J. The Radiation Regime and}

Architecture of Plant Stands. The Hague: Dr Junk W, 1981.

SAILOR, D. J. Simulated Urban Climate Response to Modifications in Surface Albedo and Vegetative Cover. Journal of Applied Meteorology, v. 34, n. 7, p. 1694-1704, 1995.

SANTAMOURIS, M. Energy and Climate in the Urban Built Environment. London: James and James, 2001.

SHASHUA-BAR, L.; HOFFMAN, M. E. Quantitative Evaluation of Passive Cooling of the UCL Microclimate in Hot Regions in Summer case study: urban streets and courtyards with trees. Journal of Building and Environment, v. 39, p. 1087-1099, 2004.

SHASHUA-BAR, L.; PEARLMUTTER, D.; ERELL, E. The Influence of Trees and Grass on Outdoor Thermal Comfort in a Hot-Arid Environment. International Journal of Climatology, v. 31, n. 10, p. 1498-1506, 2010.

SHINZATO, P.; DUARTE, D.; YOSHIDA, D. F. O. O Impacto da Vegetação nos Microclimas Urbanos: estimativa do índice de áreas foliar IAF pelo método de fotos hemisféricas. In: ENCONTRO NACIONAL, 13.; LATINOAMERICANO DE CONFORTO NO AMBIENTE CONSTRUÍDO, 9., Campinas, 2015. Anais... Campinas, 2015.

SPRONKEN-SMITH R. A.; OKE T. R. Scale Modelling of Nuctural Cooling in Urban Parks. Boundary-Layer Meteorology, v. 93, p. 287-312 1999.
STONE, B. The City and the Coming Climate: climate change in the places we live. New York: Cambridge University Press, 2012.

WEISS, M. et al. Review of Methods for in situ Leaf Area Index (LAI) Determination Part II. Estimation of LAI, Errors and Sampling. Agricultural and Forest Meteorology, v. 121, p. 37-53, 2004.

WIERNERT, U.; KUTTLER, W.The Dependence of the Urban Heat Island Intensity on Latitude: a statistical approach. MeteorologischeZeitschrift, v. 14, p. 677-686, 2005.

WILLMOTT, C. J. On the Validation of Models. Physical Geography, v. 2, p. 184-194, 1981.

ZHENG, G.; MOSKAL, L. M. Retrieving Leaf Area Index (LAI) Using Remote Sensing: theories, methods and sensors. Sensors, v. 9, n. 4, p. 27192745, 2009.

\section{Agradecimentos}

Esta pesquisa teve o apoio da Fundação de Amparo à Pesquisa do Estado de São Paulo - FAPESP (processo n. 2010/ 51125-0), da Coordenação de Aperfeiçoamento de Pessoal de Nível Superior CAPES e do Conselho Nacional de Desenvolvimento Científico e Tecnológico - CNPq. Os autores agradecem ao grupo de pesquisa do Labaut pela assistência nos levantamentos de campo e à Secretaria do Verde Meio Ambiente pela autorização e apoio nos estudos do Parque Trianon. Agradecemos também ao Prof. Dr. Humberto R. da Rocha do Instituto de Astronomia, Geofísica e Ciências Atmosféricas (IAG) da Universidade de São Paulo (USP) pelos dados de solo e à Profa. Eleonora Sad de Assis pelo apoio no processo de calibração do modelo. Agradecemos também ao Laboratório MASTER - Meteorologia aplicada a sistemas de tempo regionais pela cessão dos dados do Aeroporto de Congonhas e ao IAG da USP pelos dados da estação meteorológica na Água Funda. 


\section{Paula Shinzato}

Departamento de Tecnologia da Arquitetura, Faculdade de Arquitetura e Urbanismo | Universidade de São Paulo | Rua do Lago, 876, LABAUT, Cidade Universitária | São Paulo - SP - Brasil | CEP 05508-080 | Tel.: (11) 3091-8625 | E-mail: paulashinzato@yahoo.com

\section{Denise Helena Silva Duarte}

Departamento de Tecnologia da Arquitetura, Faculdade de Arquitetura e Urbanismo | Universidade de São Paulo | Rua do Lago, 876, Cidade Universitária | São Paulo - SP - Brasil | CEP 05508-900 | Tel.: (11) 3091-8625 | E-mail: dhduarte@me.com

\section{Revista Ambiente Construído}

Associação Nacional de Tecnologia do Ambiente Construído

$$
\begin{aligned}
& \text { Av. Osvaldo Aranha, } 99 \text { - 3o andar, Centro } \\
& \text { Porto Alegre - RS - Brasil } \\
& \text { CEP 90035-190 } \\
& \text { Telefone: }+55 \text { (51) 3308-4084 } \\
& \text { Fax: }+55 \text { (51) 3308-4054 } \\
& \text { www. seer. ufrgs. br/ambienteconstruido } \\
& \text { E-mail: ambienteconstruido@ufrgs.br }
\end{aligned}
$$

